\title{
Improved Control of Green Mold of Citrus with Imazalil in Warm Water Compared with Its Use in Wax
}

J. L. Smilanick, Horticultural Crops Research Laboratory, USDA-ARS, 2021 South Peach Avenue, Fresno, CA 93727; I. F. Michael and M. F. Mansour, Advanced Packinghouse Systems, LLC, 1927 Cherry Avenue, Fresno, CA 93791; B. E. Mackey, Biometrics Unit, USDA-ARS, 800 Buchanan Street, Albany, CA 94710; D. A. Margosan, Horticultural Crops Research Laboratory, USDA-ARS, 2021 South Peach Avenue, Fresno, CA 93727; D. Flores, Diversified Agricultural Consultants, Upland, CA 91786; and C. F. Weist, Advanced Packinghouse Systems, LLC, 1927 Cherry Avenue, Fresno, CA 93791

\begin{abstract}
Smilanick, J. L., Michael, I. F., Mansour, M. F., Mackey, B. E., Margosan, D. A., Flores, D., and Weist, C. F. 1997. Improved control of green mold of citrus with imazalil in warm water compared with its use in wax. Plant Dis. 81:1299-1304.

The effectiveness of imazalil for the control of citrus green mold (caused by Penicillium digitatum) improved significantly when fruit were treated with heated aqueous solutions of the fungicide as compared with the current commercial practice of spraying wax containing imazalil on fruit. When applied at less than $500 \mu \mathrm{g} \cdot \mathrm{ml}^{-1}$ in solutions heated to $37.8^{\circ} \mathrm{C}$, control of postharvest green mold of citrus was significantly superior to applications of $4,200 \mu \mathrm{g} \cdot \mathrm{ml}^{-1}$ imazalil in wax sprayed on fruit at ambient temperatures. The improvement in imazalil efficacy was obtained with a decrease in fungicide residues on the fruit. Residues of about $3.5 \mu \mathrm{g} \cdot \mathrm{g}^{-1}$ imazalil deposited by the application of imazalil in wax reduced the incidence of green mold on lemons from $94.4 \%$ among untreated controls to $15.1 \%$, whereas an equal residue deposited by passing fruit through heated aqueous imazalil reduced green mold incidence to $1.3 \%$. Similar differences were found in tests with oranges. Residues of 2 and $3.5 \mu \mathrm{g} \cdot \mathrm{g}^{-1}$ imazalil were needed to control the sporulation of $P$. digitatum on oranges and lemons, respectively. The mode of application of imazalil did not influence control of sporulation. The influence of immersion time, imazalil concentration, and solution temperature on imazalil residues on oranges and lemons was determined in tests using commercial packing equipment, and a model that describes residue deposition was developed. Residues after a 30 - or 60 -s treatment in heated aqueous imazalil were sufficient to control sporulation, but residues after 15-s treatments were too low and required an additional application of $1,070 \mu \mathrm{g} \cdot \mathrm{ml}^{-1}$ imazalil in wax to deposit an amount of imazalil sufficient to control sporulation. An imazalil-resistant isolate of $P$. digitatum was significantly controlled by heated aqueous imazalil. The incidence of green mold of navel oranges was reduced from 98.8 to $17.4 \%$ by treatment in $410 \mu \mathrm{g} \cdot \mathrm{ml}^{-1}$ imazalil at $40.6^{\circ} \mathrm{C}$ for $90 \mathrm{~s}$. However, control of the resistant isolate required imazalil residues on the fruit of $7.9 \mu \mathrm{g} \cdot \mathrm{g}^{-1}$, which is within the U.S. tolerance of $10 \mu \mathrm{g} \cdot \mathrm{g}^{-1}$ but above the $5 \mu \mathrm{g} \cdot \mathrm{g}^{-1}$ tolerance of some countries that import citrus fruit from the United States.
\end{abstract}

Imazalil is a fungicide registered for postharvest application to citrus fruit to reduce both the incidence of decay and sporulation of Penicillium digitatum (Pers.:Fr.) Sacc., cause of citrus green mold. In Arizona and California, imazalil is usually added to fruit waxes and applied to fruit as a non-recovery spray over rotating brushes. This method is used because it is convenient and effective, although Brown and coworkers $(2,4)$ showed that imazalil, unlike other fungicides used for this purpose, controlled green mold sig-

Corresponding author: J. L. Smilanick

E-mail: Jsmilanick@aol.com

Accepted for publication 1 August 1997.

Publication no. D-1997-0829-01R

This article is in the public domain and not copyrightable. It may be freely reprinted with customary crediting of the source. The American Phytopathological Society, 1997. nificantly better when applied in water than when applied in wax. Similarly, other researchers $(8,15,16)$ reported superior control of green mold by the application of aqueous as compared with wax imazalil formulations. Imazalil loses effectiveness in wax because a substantial portion of the residue remains immobilized in the wax, and because waxes are more viscous than water, they less effectively penetrate the small wound infection courts that are exploited by $P$. digitatum on the rind of citrus fruit (2).

One reason the application of imazalil in wax has continued, in addition to its convenience, is its reliable control of $P$. digitatum sporulation. Anti-sporulant activity is important because it controls a condition termed soilage, a cosmetic defect that occurs when healthy fruit within cartons are soiled by spores from adjacent decayed fruit (7). Reducing sporulation also reduces the airborne inoculum within citrus packinghouses. This is particularly important because the inoculum within packinghouses is often composed of fungicideresistant isolates (8). Brown and Dezman (3) reported that control of sporulation on Valencia oranges with aqueous, nonrecovery sprays of imazalil or imazalil in wax both required a residue of about 2 $\mu \mathrm{g} \cdot \mathrm{g}^{-1}$ fresh fruit weight. However, with a non-recovery aqueous spray, coverage sufficient for sporulation control required better contact between brushes and fruit than was achieved in many commercial packinghouses. Therefore, in commercial packinghouses in Florida where imazalil is applied in aqueous sprays, this is followed by a second application of 1,000 to 2,000 $\mu \mathrm{g} \cdot \mathrm{g}^{-1}$ imazalil in wax. Fruit treated in this manner have residues of about $4 \mu \mathrm{g} \cdot \mathrm{g}^{-1}$, which is within the tolerance of $10 \mu \mathrm{g} \cdot \mathrm{g}^{-1}$ in the United States and the $5 \mu \mathrm{g} \cdot \mathrm{g}^{-1}$ tolerance of most importing countries (6).

An alternative to optimize the efficacy of imazalil would be to apply the fungicide by immersing fruit in heated aqueous solutions of the fungicide. Rapid treatment, an important attribute when very large numbers of fruit are processed, would be facilitated because imazalil residues accumulate on oranges about three times faster when the fruit are dipped in the fungicide rather than sprayed with it (3). Heating fungicide solutions also accelerates the accumulation of fungicide residues in fruit (19). Sufficient residues from a heated aqueous imazalil solution could control sporulation of $P$. digitatum and make a second application of imazalil in wax, such as is needed after aqueous sprays, unnecessary. Efficacy is also improved by heating. The control of postharvest decay by imazalil on mangos (22), grapefruit (14), and lemons $(18,19)$ was enhanced when the fungicide was heated. Furthermore, a synergistic interaction between heat and imazalil treatment might provide better control of imazalil-resistant isolates than imazalil applied alone.

The purpose of this work was to determine with commercial-scale packing equipment the influence of immersion time, imazalil concentration, and temperature on concentration of imazalil residues in citrus fruit; to compare the efficacy of optimal regimes of imazalil applied in 
heated solutions to the conventional industry practice of spraying imazalil in wax on fruit for the control of green mold; and to determine if an imazalil-resistant isolate of $P$. digitatum could be adequately controlled by applying heated imazalil solutions.

\section{MATERIALS AND METHODS}

Fruit and packing line configuration. Sweet orange (Citrus sinensis [L.] Osbeck) cultivars Valencia and Washington and lemon (C. lemon [L.] N. L. Burm.) cultivar Eureka grown in the San Joaquin Valley of California were commercially harvested 1 to 2 days before they were selected by hand from field bins and randomized. When inoculated, they were inoculated once each about $24( \pm 2)$ h before treatment. The internal temperature of the fruit was $18-20^{\circ} \mathrm{C}$. All treatments were applied on a commercial-scale packing line to four replicates of 60 oranges or 75 lemons each. A fifth replicate of 30 to 50 uninoculated fruit was included in some tests for residue analysis and later inoculation in sporulation tests. The temperatures of fruit were monitored with 1-mm-diameter, copperconstantan probes (Gaffney Engineering, Gainesville, FL) attached to a thermocouple thermometer (model HH11, Omega Engineering, Stamford, CT). The temperatures of air or water were monitored with a 3 -mm-diameter by 30 -cm-long corrosion-resistant, copper-constantan probe (model TJ48, Omega Engineering) attached to the same thermocouple thermometer. The temperatures of water or imazalil solutions reported are $\pm 0.5^{\circ} \mathrm{C}$.

Each replicate was placed on the packing line just before a high-pressure washer. The residence time in the high-pressure washer, operating at 1,500 Newtons pressure, was $12 \mathrm{~s}$. The water in the pressure washer contained 10 to $50 \mu \mathrm{g} \cdot \mathrm{ml}^{-1}$ sodium hypochlorite at $\mathrm{pH}$ 7.2. After the highpressure washer, the fruit passed for 15 to $20 \mathrm{~s}$ over rotating brushes through a dryer operating at $32.2^{\circ} \mathrm{C}$ to a moving belt sorting table, where decayed or damaged fruit were removed, and passed into a $2,400-\mathrm{L}$

Table 1. Influence of imazalil concentration, temperature, and immersion period on on imazalil residues $\left(\mu \mathrm{g} \cdot \mathrm{g}^{-1}\right)$ on Valencia oranges

\begin{tabular}{lcccc}
\hline \multirow{2}{*}{$\begin{array}{l}\text { Imazalil } \\
\left(\boldsymbol{\mu g} \cdot \mathbf{m l}^{-1}\right)\end{array}$} & Temperature $\left({ }^{\circ} \mathbf{C}\right)$ & $\mathbf{1 5}$ & $\mathbf{3 0}$ & $\mathbf{6 0}$ \\
\cline { 3 - 5 } & 32.2 & $1.04(1.18)^{\mathrm{a}}$ & $1.21(1.30)$ & $1.29(1.55)$ \\
153 & 37.8 & $1.09(0.90)$ & $1.45(1.36)$ & $2.41(2.29)$ \\
153 & 43.3 & $1.26(1.66)$ & $2.85(2.46)$ & $4.20(4.06)$ \\
153 & 32.2 & $1.24(1.38)$ & $2.02(1.59)$ & $2.95(2.03)$ \\
244 & 37.8 & $1.39(1.12)$ & $1.54(1.87)$ & $2.24(3.38)$ \\
244 & 43.3 & $2.17(1.90)$ & $2.82(3.19)$ & $5.85(5.76)$ \\
244 & 32.2 & $2.05(2.57)$ & $2.94(2.88)$ & $3.26(3.50)$ \\
335 & 37.8 & $2.88(2.33)$ & $3.78(3.38)$ & $5.35(5.47)$ \\
335 & 43.3 & $2.84(3.14)$ & $4.71(4.91)$ & $8.84(8.45)$ \\
335 & &
\end{tabular}

${ }^{a}$ Each value $\left(\mu \mathrm{g} \cdot \mathrm{g}^{-1}\right)$ is the mean of two analyses. Values in parentheses are predicted by a second order surface model. Imazalil residues $=25.74-0.0117(I C)-1.25(T)-0.000345(I C * T)-$ $0.00662(t)-0.000761(I C * t)+0.000134(T * t)+0.0000258(I C * T * t)+0.0000604(I C)^{2}+$ $0.0170(T)^{2}$. IC = aqueous imazalil concentration $\left(\mu \mathrm{g} \cdot \mathrm{ml}^{-1}\right) ; T=$ aqueous imazalil solution temperature $\left({ }^{\circ} \mathrm{C}\right)$; and $t=$ immersion time (s) in aqueous imazalil. the percentage of the fruit surface covered with green mold spores was used where 5 $=100 \% ; 4=90-99 \% ; 3=50-89 \% ; 2=$ $11-49 ; 1=1-10 \% ; 0=0 \%$. Each value represented the mean of sporulation ratings for 12 to 15 fruit per treatment.

Imazalil analyses. Imazalil residues on fruit are expressed as $\mu \mathrm{g} \cdot \mathrm{g}^{-1}$ fresh weight. Because the surface to mass ratio will change with fruit size, and presumably influence the quantity of residue per gram of fruit weight, the orange and lemons selected for analysis were of uniform size and represented common commercial size classes. The oranges were $7 \mathrm{~cm}$ in diameter. The lemons were $7.5 \mathrm{~cm}$ in length and $5.5 \mathrm{~cm}$ wide. Imazalil residues in fruit were determined from two replicates of eight fruit each. Each fruit was sliced into eight portions, and one portion from each of the eight fruit was combined before analysis to comprise one replicate. To the combined fruit portions, a water volume one-half the weight of the fruit sample was added, blended at high speed in a blender, and an aliquot extracted with $10 \%(\mathrm{w} / \mathrm{v})$ sodium hydroxide saturated with sodium chloride, followed by the addition of ethyl acetate. The suspension was briefly macerated in a homogenizer, mixed by rotation for $30 \mathrm{~min}$, centrifuged, an aliquot of the supernatant (ethyl acetate layer) was then removed. After $0.05 \mathrm{~N} \mathrm{H}_{2} \mathrm{SO}_{4}$ was added to this aliquot, it was shaken vigorously for $2 \mathrm{~min}$, the ethyl acetate layer was discarded, and the aqueous layer was adjusted to $\mathrm{pH} 9$ to 10 with sodium hydroxide and trisodium phosphate buffer. An aliquot of ethyl acetate was added and shaken vigorously. The ethyl acetate layer was removed, dried with anhydrous sodium sulfate, and analyzed by gas chromatography with an electron capture detector. Recovery of imazalil from fruit portions spiked with 1 to $5 \mu \mathrm{g} \cdot \mathrm{g}^{-1}$ imazalil was about $95 \%$. The imazalil content of water or wax solutions was determined by analysis. Water or wax solutions of imazalil were extracted with ethyl acetate, dried with sodium sulfate, and analyzed by gas chromatography.

Influence of fungicide concentration, temperature, and immersion period on imazalil residues. To determine the influence of imazalil (Fungaflor 500EC, 44.6\% a.i.; Janssen Pharmaceutica, Titusville, NJ) concentration, tank temperature, and immersion time on imazalil residues on $\mathrm{Va}$ lencia oranges, the fruit were pressure washed with water and immersed in 0,153 , 244 , or $335 \mu \mathrm{g} \cdot \mathrm{ml}^{-1}$ imazalil at $32.2,37.8$, or $43.3^{\circ} \mathrm{C}$ for 15,30 , or $60 \mathrm{~s}$. After treatment, the oranges were dried in the first stage of the packing line dryer as previously described; waxed with a high solids content, shellac-based organic finishing wax on the packing line; and dried in the second stage of packing line dryer as previously described. To determine the influence of imazalil concentration, tank temperature, and immersion time on residues 
on lemons, the fruit were pressure washed with water and immersed in $0,93,160$, or $405 \mu \mathrm{g} \cdot \mathrm{ml}^{-1}$ imazalil heated to $32.2,37.8$, or $43.3^{\circ} \mathrm{C}$ for 15,30 , or $60 \mathrm{~s}$. After treatment, the lemons were dried in the first stage of the packing line dryer as previously described, waxed with a water-emulsion lemon storage wax, and dried in air on wire screens. Fruit were stored at $10^{\circ} \mathrm{C}$ and the imazalil content of the fruit analyzed within 7 days as previously described.

Comparison of imazalil efficacy when applied in wax or in water heated to $\mathbf{3 7 . 8}^{\circ} \mathbf{C}$. To compare the influence of imazalil (Fungaflor 500EC) applied in wax or in water heated to $37.8^{\circ} \mathrm{C}$ on control of the incidence and sporulation of $P$. digitatum using oranges and lemons, all fruit were inoculated with isolate M6R $24 \mathrm{~h}$ before treatment. Fruit were pressure washed with water, then treated with imazalil by: 1) immersion in 136, 240, 350, or $490 \mu \mathrm{g} \cdot \mathrm{ml}^{-1}$ imazalil at $37.8^{\circ} \mathrm{C}$ for $15 \mathrm{~s}$, dried in the first stage of the packing line dryer, waxed, and dried in the second stage of the packing line dryer as previously described; or 2) after drying in the first stage of the packing line dryer, they were sprayed with a high solids content, shellacbased organic finishing wax containing $1,100,2,200,3,400$, or $4,200 \mu \mathrm{g} \cdot \mathrm{ml}^{-1}$ imazalil, and dried in the second stage of the packing line dryer as previously described. Fruit were stored at $10^{\circ} \mathrm{C}$ and the imazalil content of the fruit analyzed within 7 days as previously described. Green mold incidence and sporulation of $P$. digitatum was determined as previously described.

Preliminary tests showed fruit immersed in heated aqueous solutions of imazalil for $15 \mathrm{~s}$ or less often had imazalil residues too low to control sporulation of $P$. digitatum, therefore, the heated imazalil treatments were followed by a spray of imazalil in wax to increase imazalil residues. Lemons were treated by immersing in $0,93,160$, or $405 \mu \mathrm{g} \cdot \mathrm{ml}^{-1}$ imazalil heated to $32.2,37.8$, or $43.3^{\circ} \mathrm{C}$ for $15 \mathrm{~s}$, dried in the first stage packing line dryer as previously described, waxed with water-emulsion lemon storage wax alone or storage wax containing 1,070 or $1,910 \mu \mathrm{g} \cdot \mathrm{ml}^{-1}$ imazalil, and dried in air on wire screens. Fruit were stored at $10^{\circ} \mathrm{C}$ and the imazalil content of the fruit analyzed within 7 days as previously described.

Control of imazalil-sensitive or imazalil-resistant $\boldsymbol{P}$. digitatum isolates. Navel oranges were inoculated using two $P$. digitatum isolates, imazalil-sensitive isolate M6R or imazalil-resistant isolate 151 , incubated $24 \mathrm{~h}$ at $20^{\circ} \mathrm{C}$, and immersed in 247 or $410 \mu \mathrm{g} \cdot \mathrm{ml}^{-1}$ imazalil (Magnate Sulfate 750 WP, $75 \%$ a.i.; Makhteshim Agan, Republic of South Africa) heated to 21.1 or $40.6^{\circ} \mathrm{C}$ for $90 \mathrm{~s}$; dried in the first stage of the packing line dryer as previously described, waxed with a high solids content, shellac-based organic finishing wax; and dried in the last stage of the packing line dryer as previously described. Fruit were stored at $10^{\circ} \mathrm{C}$ and the imazalil content of the fruit analyzed within 7 days as previously described. Green mold incidence and sporulation of $P$. digitatum were determined as previously described.

Statistical analyses. Imazalil residues, the incidence of green mold, and sporulation of $P$. digitatum were analyzed by twoor three-way analysis of variance. An arcsin transformation of the square root of the proportion of decayed fruit was applied before analysis of the incidence of green mold. Duncan's new multiple range test $(P$ $=0.05)$ to separate means or orthogonal contrasts were applied to compare treatments. A second order response surface model was fitted using SAS PROC GLM (SAS/STAT, Vers. 6, 4th Ed., Cary, NC) to predict the residues and $95 \%$ confidence intervals (CI). Regression expressions describing the relationship between sporulation indices and imazalil residues were fitted using Cricket Graph III (1).

\section{RESULTS}

Influence of fungicide concentration, temperature, and immersion period on imazalil residues. Increasing the temperature, immersion time, or imazalil concentration increased imazalil residues on Valencia oranges (Table 1) and Eureka lemons (Table 2). Doubling the imazalil concentration, doubling the immersion time, or increasing the solution temperature by $5.6^{\circ} \mathrm{C}$ increased imazalil residues approximately one and one-half to two times on the fruit. Separate second order models describing imazalil residues for oranges and lemons were prepared that can be used to predict residues. Residues predicted by both models were similar to those measured (Tables 1 and 2).

Table 2. Influence of imazalil concentration, temperature, and immersion period on imazalil residues $\left(\mu \mathrm{g} \cdot \mathrm{g}^{-1}\right)$ on Eureka lemons

\begin{tabular}{lcccc}
\hline \multirow{2}{*}{$\begin{array}{l}\text { Imazalil } \\
\left(\boldsymbol{\mu g} \cdot \mathbf{m l}^{\mathbf{- 1}}\right)\end{array}$} & Temperature $\left({ }^{\circ} \mathbf{C}\right)$ & $\mathbf{1 5}$ & $\mathbf{3 0}$ & $\mathbf{6 0}$ \\
\cline { 4 - 5 } & 32.2 & $0.22(0.25)^{\mathrm{a}}$ & $0.33(0.36)$ & $0.46(0.43)$ \\
93 & 37.8 & $0.34(0.36)$ & $0.57(0.47)$ & $0.60(0.64)$ \\
93 & 43.3 & $0.50(0.44)$ & $0.61(0.62)$ & $0.94(0.96)$ \\
93 & 32.2 & $0.54(0.50)$ & $0.58(0.64)$ & $0.84(0.84)$ \\
160 & 37.8 & $0.68(0.67)$ & $1.07(0.92)$ & $1.58(1.37)$ \\
160 & 43.3 & $0.79(0.88)$ & $1.18(1.30)$ & $2.11(2.21)$ \\
160 & 32.2 & $0.92(0.91)$ & $1.42(1.27)$ & $1.75(1.94)$ \\
405 & 37.8 & $1.42(1.39)$ & $1.77(2.07)$ & $3.88(3.62)$ \\
405 & 43.3 & $2.06(2.09)$ & $3.70(3.34)$ & $6.65(6.67)$ \\
405 & & &
\end{tabular}

${ }^{a}$ Each value $\left(\mu \mathrm{g} \cdot \mathrm{g}^{-1}\right)$ is the mean of two analyses. Values in parentheses are predicted by a second order surface model. The natural logarithm of imazalil residues in lemons $=-7.87+2.27 * \log _{\mathrm{e}} I C-$ $0.918^{*}(T)+0.0257 *\left(\log _{\mathrm{e}} I C^{*} T\right)-0.0307 * t+0.00579\left(\log _{\mathrm{e}} I C^{*} t\right)+0.000807 *\left(T^{*} t\right)-0.229^{*}$ $\log _{\mathrm{e}} I C^{2}-0.00178 * \mathrm{t}^{2} . I C=$ aqueous imazalil concentration $\left(\mu \mathrm{g} \cdot \mathrm{ml}^{-1}\right) ; T=$ aqueous imazalil solution temperature $\left({ }^{\circ} \mathrm{C}\right)$; and $t=$ immersion time (s) in aqueous imazalil.

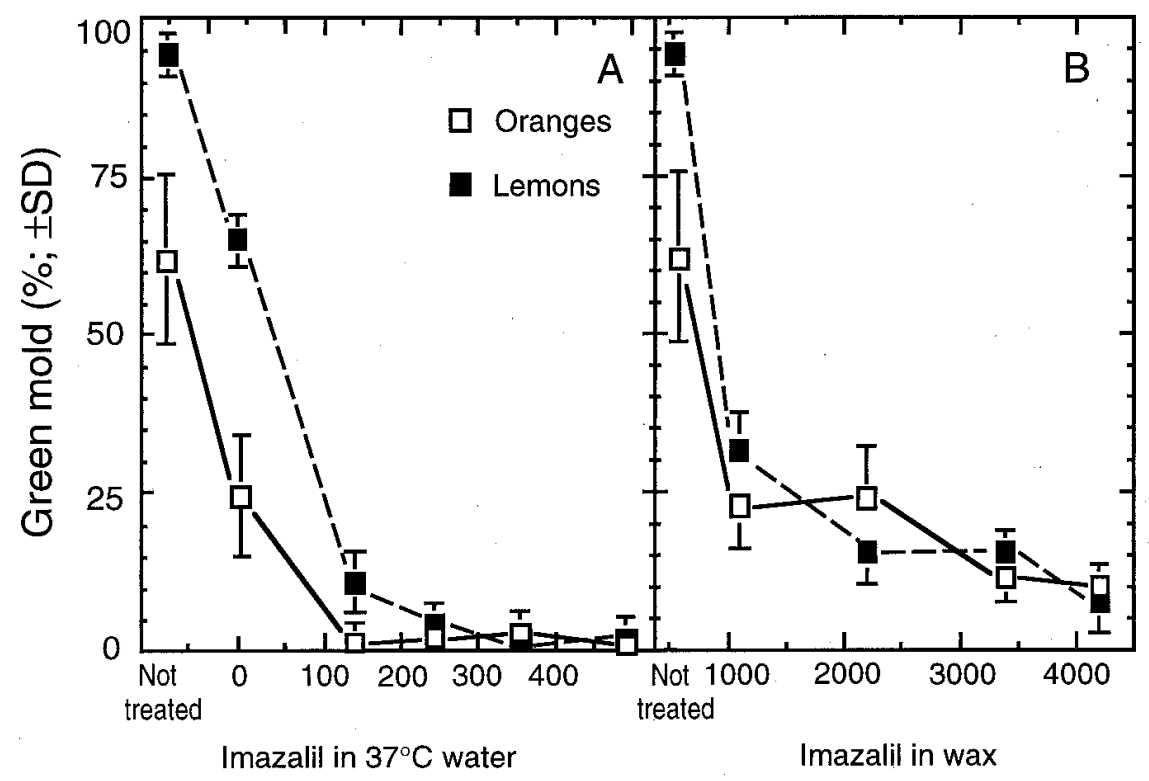

Fig. 1. Influence of imazalil concentration $(\mu \mathrm{g} / \mathrm{ml})$ and method of application on the incidence of postharvest green mold of oranges and lemons. The fruit were (A) immersed for $15 \mathrm{~s}$ in imazalil in water at $37^{\circ} \mathrm{C}$ or $(\mathbf{B})$ sprayed with imazalil in wax over rotating brushes at $23^{\circ} \mathrm{C}$. All fruit were inoculated $24 \mathrm{~h}$ before treatment with spores of Penicillium digitatum. 
Comparison of imazalil efficacy when applied in wax or in water heated to $37.8^{\circ} \mathbf{C}$. The control of green mold on oranges and lemons was significantly superior $(P<0.0001$, orthogonal contrast $)$ by imazalil applied in heated water to that in wax (Fig. 1), although the imazalil residues deposited on the fruit significantly exceeded $(P<0.0001$, orthogonal contrast $)$ those of imazalil applied in heated water (Fig. 2). Residues of about $3.5 \mu \mathrm{g} \cdot \mathrm{g}^{-1}$ imazalil deposited by the application of imazalil in wax reduced the incidence of green mold on lemons from $94.4 \%$ among untreated controls to about $11.0 \%$, whereas an equal residue deposited by passing fruit through heated aqueous imazalil reduced green mold incidence to less than $1.0 \%$ (Fig. 2). Similar differences occurred with oranges. Treatment with water at $37.8^{\circ} \mathrm{C}$ reduced green mold incidence of oranges and lemons by about 30 and $55 \%$, respectively. Residues of 2 and $3.5 \mu \mathrm{g} \cdot \mathrm{g}^{-1}$ imazalil were needed to control sporulation on oranges and lemons, respectively (Fig. 3). Because control of sporulation by imazalil applied in water or wax sporulation was not significantly different, all rating of control of sporulation were pooled.

Augmentation of imazalil residues by a second application of imazalil in wax, in order to obtain residue levels sufficient to control $P$. digitatum sporulation, were most effectively achieved by a concentration of $1,070 \mu \mathrm{g} \cdot \mathrm{ml}^{-1}$ imazalil in the wax (Table $3)$. When the second application of wax with $1,910 \mu \mathrm{g} \cdot \mathrm{ml}^{-1}$ imazalil was applied, residues were higher than needed to control sporulation and above the $5 \mu \mathrm{g} \cdot \mathrm{g}^{-1}$ imazalil residue tolerance for citrus fruit of many importing countries.

Control of imazalil-sensitive or imazalil-resistant $\boldsymbol{P}$. digitatum isolates.

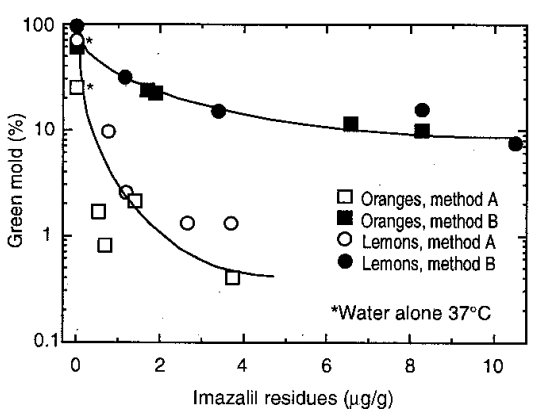

Fig. 2. The relationship between imazalil residues on fruit and the method of application of imazalil on the incidence of postharvest green mold of oranges and lemons. In method A, the fruit were immersed for $15 \mathrm{~s}$ in $136-490$ $\mu \mathrm{g} \cdot \mathrm{ml}^{-1}$ imazalil in water at $37^{\circ} \mathrm{C}$. The incidence of green mold $=1.995$ (imazalil residue $)^{-0576}, r^{2}=0.62$. In method $\mathrm{B}$, the fruit were sprayed with 1,100 to $4,200 \mu \mathrm{g} \cdot \mathrm{ml}^{-1}$ imazalil in wax over rotating brushes at $23^{\circ} \mathrm{C}$. The incidence of green mold $=-20.421 *$ $\log$ (imazalil residue) $+29.23, r^{2}=0.89$. All fruit were inoculated $24 \mathrm{~h}$ before treatment with spores of Penicillium digitatum.
Growth of mycelial plugs of isolates M6R and 151 was stopped in PDA with imazalil concentrations of $0.1 \mu \mathrm{g} \cdot \mathrm{ml}^{-1}$ and more than $2 \mu \mathrm{g} \cdot \mathrm{ml}^{-1}$, respectively. Heating the imazalil solution increased residues in navel oranges and improved control of both $P$. digitatum isolates (Fig. 4). Control of imazalil-sensitive isolate M6R was superior to control of imazalil-resistant isolate 151. Heating $410 \mu \mathrm{g} \cdot \mathrm{ml}^{-1}$ imazalil from 21.1 to $40.6^{\circ} \mathrm{C}$ further reduced green mold incidence from 16.2 to $5.3 \%$ among oranges inoculated with isolate M6R, and from 71.2 to $17.4 \%$ among oranges inoculated with isolate 151 . Heating $410 \mu \mathrm{g}-\mathrm{ml}^{-1}$ imazalil from 21.1 to $40.6^{\circ} \mathrm{C}$ also increased imazalil residues on oranges three- to fourfold. Sporulation of the sensitive isolate was controlled by all imazalil treatments, while sporulation of the imazalil-resistant isolate was not controlled (data not shown). Treatment with water alone at $40.6^{\circ} \mathrm{C}$ had no significant influence on the incidence of green mold in this test.

\section{DISCUSSION}

The higher effectiveness of imazalil shown in this study was due to three factors: i) application of the imazalil in water instead of wax; ii) heating of the aqueous imazalil solution; and iii) immersing the fruit in a tank of the solution instead of spraying the fungicide on fruit to make the treatment brief enough to be practical. In our tests, fruit immersed briefly in heated aqueous imazalil, leaving residues of 1 to 3 $\mu \mathrm{g} \cdot \mathrm{g}^{-1}$, had about $95 \%$ less green mold than control fruit, while similar residues deposited by spraying fruit with imazalil in wax reduced green mold incidence only about $60 \%$. Several aspects of this work were established in prior studies. Eckert et al.

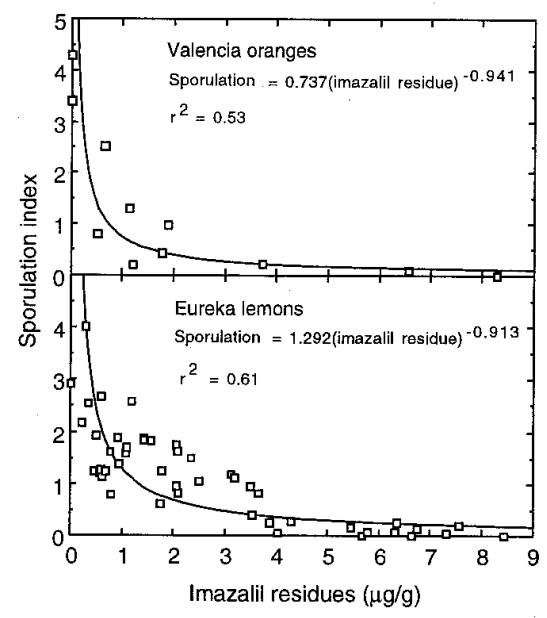

Fig. 3. Influence of imazalil residues on the sporulation of Penicillium digitatum on green mold infected oranges and lemons stored $3 \mathrm{wk}$ at $10^{\circ} \mathrm{C}$ after imazalil treatment. The sporulation index describes the percentage of the fruit surface covered with green mold spores where $5=100 \% ; 4=90-99 \% ; 3=50-89 \% ; 2=11-$ $49 ; 1=1-10 \%$; and $0=$ no sporulation on the surface of the fruit.
(8) showed imazalil reduced green mold more effectively when applied in water instead of wax. Imazalil applied at 2000 $\mu \mathrm{g} \cdot \mathrm{ml}^{-1}$ in wax or in water reduced the incidence of green mold by 48 and $98 \%$, respectively. Brown and Dezman (3) reported that application of aqueous solutions of imazalil by immersion in a tank deposited imazalil residues approximately three times faster than spraying the same solution on citrus fruit. Heating imazalil improved its effectiveness on mangos (22), grapefruit (14), and lemons $(18,19)$. Temperatures we used are too low to reliably control green mold by heat (20), although partial control of green mold by heated water alone did occasionally occur in our work.

Imazalil residues required to control green mold sporulation we report are slightly higher those reported by others. Most researchers reported residues of about 1 to $2 \mu \mathrm{g} \cdot \mathrm{g}^{-1}$ were needed to control sporulation on oranges and lemons $(3,13)$, whereas we found 2 and $3.5 \mu \mathrm{g} \cdot \mathrm{g}^{-1}$ were needed, probably because of differences in incubation temperatures of the fruit or the subjectivity of sporulation indices. Brown and Dezman (3) reported that control of sporulation of the green mold fungus on Valencia oranges with aqueous, nonrecovery sprays of imazalil required a residue of about $2 \mu \mathrm{g} \cdot \mathrm{g}^{-1}$, the same level required when imazalil is applied in wax (13). They (3) showed control of sporulation on Valencia oranges with aqueous

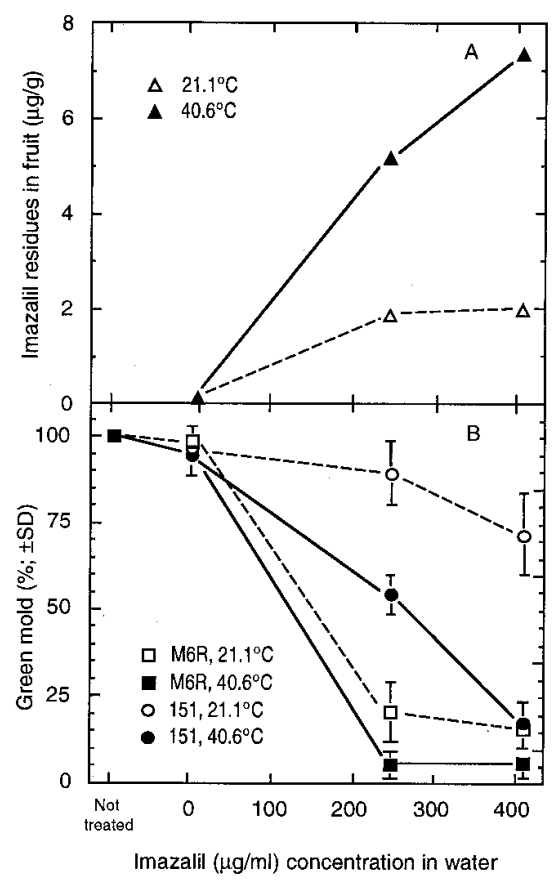

Fig. 4. Imazalil residues (A) and the incidence of green mold (B) of navel oranges immersed in imazalil in water at 21.1 or $40.6^{\circ} \mathrm{C}$ for $90 \mathrm{~s}$. All fruit were inoculated $24 \mathrm{~h}$ before treatment with spores of imazalil-sensitive isolate M6R or imazalil-resistant isolate 151 of Penicillium digitatum. 
imazalil depended on the deposition of imazalil in natural epicuticular wax, when the wax was removed, residues of $2 \mu \mathrm{g} \cdot \mathrm{g}^{-1}$ did not control sporulation. Brown and Dezman (3) stated sufficient coverage to get control of sporulation required better contact between brushes and fruit than was achieved in many commercial packinghouses when a non-recovery aqueous imazalil spray was used; as a consequence, commercial packinghouses in Florida where imazalil is applied in aqueous sprays follow this application with imazalil in wax at 1,000 to $2,000 \mu \mathrm{g} \cdot \mathrm{g}^{-1}$ to ensure adequate control of sporulation. Our results indicate that if imazalil is applied in heated solutions for $30 \mathrm{~s}$ or longer, adequate residue deposition can occur to make a second application of imazalil in wax for sporulation control unnecessary. However, treatments using heated imazalil for $15 \mathrm{~s}$ required an additional application of 1,070 $\mu \mathrm{g} \cdot \mathrm{ml}^{-1}$ imazalil in wax to leave residues sufficient to control sporulation.

Partial control of an imazalil-resistant $P$. digitatum isolate was achieved with aqueous imazalil, but relatively high residue levels were associated with its control. We reduced the incidence of green mold on oranges after inoculation with a resistant isolate by $78 \%$ by treatment for $1 \mathrm{~min}$ in $410 \mu \mathrm{g} \cdot \mathrm{ml}^{-1}$ imazalil at $40.6^{\circ} \mathrm{C}$. However, imazalil residues in the fruit where the resistant strain was partially controlled were $7.9 \mu \mathrm{g} \cdot \mathrm{g}^{-1}$; much higher than the 1 to $2 \mu \mathrm{g} \cdot \mathrm{g}^{-1}$ required to control an imazalilsensitive isolate. Higher rates must be used with care because established tolerances can be exceeded. The U.S. imazalil tolerance is $10 \mu \mathrm{g} \cdot \mathrm{g}^{-1}$ and that of many citrusimporting countries is $5 \mu \mathrm{g} \cdot \mathrm{g}^{-1}$ (6). Although the incidence of imazalil-resistant isolates of $P$. digitatum in California is high $(8,10)$, imazalil remains a useful fungicide to manage green mold. In addition to partial control of resistant isolates with higher rates of imazalil that we and others (8) reported, other aspects of imazalilresistant isolates suggest they can be managed: i) resistant isolates are less fit than imazalil-sensitive isolates and decline in competition with sensitive strains in the absence of the fungicide $(5,11,23)$; ii) imazalil-resistant isolates primarily occur in packinghouses and not in groves, therefore imazalil effectively controls the sensitive isolates from the groves; iii) because imazalil-resistant isolates primarily occur only in packinghouses, sanitation measures can be successfully applied; and iv) although the proportion of resistant isolates collected in 26 California packinghouses was high (77.2 and $74.2 \%$ in 1990 and 1994, respectively) and it did not increase in this period (10).

No rind injury was observed in any of the our tests, and the risk of injury from heated aqueous imazalil treatments we evaluated is probably low. Rind injury from hot water alone usually does not occur below $50^{\circ} \mathrm{C}$ on lemons $(12,20)$ or oranges $(21,25)$, unless the fruit are cool and turgid at the time of treatment (9). A benefit of immersion in heated water or imazalil solutions is a reduction in the susceptibility of the fruit to subsequent chilling injury $(14,17,24)$. We did not evaluate temperatures as high as those employed in those studies, however, because good control was obtained without using higher temperatures and prior reports that the addition of imazalil to water lowers the temperature at which rind injury and internal quality changes occur in lemons $(18,19)$. Shirra et al. (19) immersed lemons in water or 250 to $1,500 \mu \mathrm{g} \cdot \mathrm{ml}^{-1}$ imazalil for $3 \mathrm{~min}$ at $50^{\circ} \mathrm{C}$ and stored them for 14 weeks at $9^{\circ} \mathrm{C}$. Imazalil-treated lemons did not differ in titratable acidity or soluble solids from untreated or watertreated fruit, but imazalil concentrations of $500 \mu \mathrm{g} \cdot \mathrm{ml}^{-1}$ or higher applied at $50^{\circ} \mathrm{C}$ caused rind injuries and increased ethanol and acetaldehyde contents. These injuries did not occur when imazalil was applied at $20^{\circ} \mathrm{C}$. To reduce the risk of injury, regimes we evaluated employed cooler $\left(43.3^{\circ} \mathrm{C}\right.$ or less), briefer (60 s or less), and lower aqueous imazalil concentrations (less than $500 \mu \mathrm{g} \cdot \mathrm{ml}^{-1}$ ) than those Schirra and coworkers $(18,19)$ showed to injure lemons.

Imazalil effectiveness on citrus can be substantially improved when the fruit are passed through heated aqueous solutions of the fungicide compared to the current commercial practice of spraying the fungicide at ambient temperatures in waxes. The improvement is probably due to more ef- fective infiltration of the fungicide into the wound infection courts that are exploited by $P$. digitatum on the rind of citrus fruit (2). From our work, $30 \mathrm{~s}$ immersion of lemons or oranges in 350 to $400 \mu \mathrm{g} \cdot \mathrm{ml}^{-1}$ imazalil heated to $37.8^{\circ} \mathrm{C}$ should deposit residues of 2 to $4 \mu \mathrm{g} \cdot \mathrm{g}^{-1}$. This regime enhanced imazalil efficacy, deposited sufficient residues to control sporulation, facilitated rapid treatment, partially controlled an imazalil-resistant isolate of $P$. digitatum, and posed minimal risk of injury to the fruit. The treatment could be shortened to $15 \mathrm{~s}$ if it is followed by the application of about $1,000 \mu \mathrm{g} \cdot \mathrm{ml}^{-1}$ imazalil in wax, or if higher imazalil concentrations or temperatures were used in tanks, although the risk of injury to the fruit may be increased.

\section{ACKNOWLEDGMENTS}

We gratefully acknowledge useful ideas and suggestions of G. E. Brown, J. W. Eckert, and William Goodwine, and the assistance of Microbac Laboratories, Inc. and Pent-A-Vate, Inc. Biological Testing and Research Laboratory with imazalil analysis, the donation of supplies by of Janssen Pharmaceutica and Makhteshim Agan, and the financial support of the California Citrus Research Board.

\section{LITERATURE CITED}

1. Anonymous. 1992. CA-Cricket Graph III for Macintosh. Computer Associates, Inc., Islandia, NY.

2. Brown, G. E. 1984. Efficacy of citrus postharvest fungicides applied in water or resin solution water wax. Plant Dis. 68:415-418.

3. Brown, G. E., and Dezman, D. J. 1990. Uptake of imazalil by citrus fruit after postharvest application and the effect of residue distribution on sporulation of Penicillium digitatum. Plant Dis. 74:927-930.

4. Brown, G. E., Nagy, S., and Maraulja, M. 1983. Residues from postharvest nonrecovery spray applications of imazalil to oranges and effects on green mold caused by Penicillium digitatum. Plant Dis. 67:954-957.

5. Davé, B., Sales, M., and Walia, M. 1989 Resistance of different strains of Penicillium digitatum to imazalil treatment in California citrus packinghouses. Proc. Fla. State Hort. Soc. 102:178-179.

6. Dezman, D. J., Nagy, S., and Brown, G. E. 1986. Postharvest fungal decay control chemicals: Treatments and residues in citrus fruits. Residue Rev. 97:37-92.

7. Eckert, J. W., and Brown, G. E. 1986 Evaluation of postharvest treatments for citrus fruits. Pages 92-97 in: Methods for Evaluating Pesticides for Control of Plant Pathogens.

Table 3. Imazalil residues $\left(\mu \mathrm{g} \cdot \mathrm{g}^{-1}\right)$ on lemons immersed for $15 \mathrm{~s}$ in water or imazalil followed by application of a storage wax containing imazalil

\begin{tabular}{|c|c|c|c|c|c|c|c|c|}
\hline \multirow[b]{2}{*}{ Imazalil $\left(\mu \mathrm{g} \cdot \mathbf{m l}^{-1}\right)$} & \multirow[b]{2}{*}{ Temperature $\left({ }^{\circ} \mathbf{C}\right)$} & \multicolumn{3}{|c|}{ Imazalil concentration in wax $\left(\mu \mathrm{g} \cdot \mathrm{ml}^{-1}\right)$} & \multirow[b]{2}{*}{ Slope } & \multirow[b]{2}{*}{ Intercept } & \multirow[b]{2}{*}{$R^{2}$} & \multirow[b]{2}{*}{$P$} \\
\hline & & $\mathbf{0}$ & 1,070 & 1,910 & & & & \\
\hline 0 & 0 & $0.00^{\mathrm{a}}$ & 1.08 & 2.34 & 0.001 & -0.067 & 0.99 & 0.072 \\
\hline 93 & 32.2 & 0.22 & 2.10 & 5.47 & 0.003 & -0.090 & 0.95 & 0.147 \\
\hline 93 & 37.8 & 0.34 & 2.49 & 6.32 & 0.003 & -0.010 & 0.95 & 0.147 \\
\hline 93 & 43.3 & 0.50 & 2.07 & 5.79 & 0.003 & 0.007 & 0.90 & 0.210 \\
\hline 160 & 32.2 & 0.54 & 3.52 & 6.37 & 0.003 & 0.457 & 0.99 & 0.036 \\
\hline 160 & 37.8 & 0.68 & 3.14 & 7.55 & 0.004 & 0.275 & 0.95 & 0.148 \\
\hline 160 & 43.3 & 0.79 & 3.17 & 5.67 & 0.003 & 0.687 & 0.99 & 0.053 \\
\hline 405 & 32.2 & 0.92 & 3.65 & 6.76 & 0.003 & 0.762 & 0.99 & 0.068 \\
\hline 405 & 37.8 & 1.42 & 4.03 & 7.33 & 0.003 & 1.216 & 0.98 & 0.087 \\
\hline 405 & 43.3 & 2.06 & 4.31 & 8.44 & 0.003 & 1.674 & 0.94 & 0.152 \\
\hline
\end{tabular}

${ }^{\mathrm{a}}$ Each value $\left(\mu \mathrm{g} \cdot \mathrm{g}^{-1}\right)$ is the mean of two analyses. 
K. D. Hickey, ed. American Phytopathological Society, St. Paul, MN.

8. Eckert, J. W., Sievert, J. R., and Ratnayake, M. 1994. Reduction of imazalil effectiveness against citrus green mold in California packinghouses by resistant biotypes of Penicillium digitatum. Plant Dis. 78:971-974.

9. Fawcett, H. S. 1936. Citrus Diseases and Their Control. 2nd ed. McGraw Hill, New York.

10. Holmes, G. J. 1995. Sensitivity of pathogenic Penicillium spp. to postharvest citrus fungicides in California. Ph.D. dissertation, University of California, Riverside.

11. Holmes, G. J., and Eckert, J. W. 1995. Relative fitness of imazalil-resistant and -sensitive biotypes of Penicillium digitatum. Plant Dis. 79:1068-1073.

12. Houck, L. G. 1967. Hot water treatments for control of Penicillium digitatum green mold of Eureka lemons. (Abstr.) Phytopathology 57:99.

13. Kaplan, H. J., and Dave, B. A. 1979. The current status of imazalil: A post harvest fungicide for citrus. Proc. Fla. State Hort. Soc. 92:37-43.
14. McDonald, R. E., Miller, W. R., McCollum, T. G., and Brown, G. E. 1991. Thiabendazole and imazalil applied at 53C reduce chilling injury of grapefruit. HortScience 26:397-399.

15. Namesny, C., and Decoud, A. P. 1988. Effectivity of imazalil, prochloraz, and TBZ applied in commercial citrus waxes. Proc. Sixth Int. Citrus Congr. 3:1435-1442.

16. Radnia, P. M., and Eckert, J. W. 1988. Evaluation of imazalil efficacy in relation to fungicide formulation and wax formulation. Proc. Sixth Int. Citrus Congr. 3:1427-1434.

17. Rodov, V., Ben-Yehoshua, S., Albagli, R., and Fang, D. Q. 1995. Reducing chilling injury and decay of stored citrus fruit by hot water dips. Postharvest Bio. Technol. 5:119-127.

18. Schirra, M., Cabras, P., Angioni, A., and Melis, M. 1996. Residue level of imazalil fungicide in lemons following prestorage dip treatment at 20 and $50^{\circ} \mathrm{C}$. J. Agric. Food Chem. 44:2865-2869.

19. Schirra, M., and Mulas, M. 1995. Influence of postharvest hot-water dip and imazalilfungicide treatments on cold-stored 'Di Massa' lemons. Adv. Hort. Sci. 9:43-46.
20. Smilanick, J. L., Margosan, D. A., Henson, D. J. 1995. Evaluation of heated solutions of sulfur dioxide, ethanol, and hydrogen peroxide to control postharvest green mold of lemons. Plant Dis. 79:742-747.

21. Smoot, J. J., and Melvin, C. F. 1965. Reduction of citrus decay by hot-water treatment. Plant Dis. Rep. 49:463-467.

22. Spalding, D. H., and Reeder, W. F. 1986. Decay and acceptability of mangos treated with combinations of hot water, imazalil, and gamma-radiation. Plant Dis. 70:1149-1151.

23. Van Gestel, J. 1988. Imazalil-sensitive and less-sensitive strains of Penicillium digitatum: Competition experiments on oranges. Proc. Sixth Int. Citrus Congr. 3:1511-11514.

24. Wild, B. L., and Hood, C. W. 1989. Hot dip treatments reduce chilling injury in long-term storage of 'Valencia' oranges. HortScience 24:109-110.

25. Williams, M. H., Brown, M. A., Vesk, M., and Brady, C. 1994. Effect of postharvest heat treatments on fruit quality, surface structure, and fungal disease in Valencia oranges. Austr. J. Exp. Agric. 34:1183-1190. 